\title{
CAPÍTULO 24: QUALIDADE DE OVOS DE GALINHA SUBMETIDOS A DIFERENTES CONDIÇÕES DE ARMAZENAMENTO E TEMPO DE ESTOCAGEM UTILIZANDO IMAGEM TÉRMICA EM NOVA ANDRADINA/MS
}

\author{
CHAPTER 24: QUALITY OF CHICKEN EGGS SUBMITTED TO DIFFERENT \\ STORAGE CONDITIONS AND STORAGE TIME USING THERMAL IMAGE IN \\ NOVA ANDRADINA/MS
}

\author{
Grazieli Suszek ${ }^{1}$; Walter Patris Freire Decleva ${ }^{2}$; Andressa Martins da Nobrega ${ }^{3}$; Ana Flávia Basso \\ Royer ${ }^{4}$ Mauro de Lima ${ }^{5}$
}

\section{Resumo}

O ovo sempre foi um alimento com alta taxa de consumo no Brasil, principalmente por ser nutricionalmente completo, possuir grande quantidade de proteína e ter um custo relativamente baixo. O presente trabalho tem como objetivo avaliar a qualidade dos ovos de poedeiras de 60 semanas da linhagem Embrapa 51 (casca marrom), sistema de criação comercial em gaiola, sob duas condições de armazenamento (temperatura não controlada e refrigerado) e em diferentes tempos de estocagem (frescos, 7, 14 e 21 dias), utilizando imagens térmicas. O experimento foi desenvolvido no IFMS campus de Nova Andradina, foram utilizados ovos de aves da linhagem Embrapa 51 presentes em um galpão para aves de postura em ambiente não controlado. Foram coletados dados de qualidade interna e externa dos ovos e obtida imagem térmica com auxilio de uma câmera Flier®. Verificou-se a existência de interdependência entre os fatores temperatura de conservação x período de estocagem dos ovos. Pelas imagens térmicas foi possivel observar que ovos refrigerados mantêm melhor estrutura, contribuído para um ovo de melhor qualidade, assim a utilização de imagem é capaz de mensurar parâmetros para análise de ovos de forma não destrutiva.

Palavras-Chaves: Flier,Temperatura, Qualidade

\begin{abstract}
The egg has always been a food with a high consumption rate in Brazil, mainly because it is nutritionally complete, has a large amount of protein and has a relatively low cost. The present work aims to evaluate the quality of the 60-week-old laying eggs of the Embrapa 51 line (brown shell), a commercial breeding system in a cage, under two storage conditions (uncontrolled and refrigerated temperature) and at different storage times. (fresh, 7, 14 and 21 days), using thermal images. The experiment was carried out on the IFMS campus of Nova Andradina, using eggs from birds of the Embrapa 51 line present in a shed for laying birds in an uncontrolled environment. Internal and external quality data of the eggs were collected and thermal image was obtained with the aid of a Flier ${ }^{\circledR}$ camera. It was verified the existence of interdependence between the factors temperature of conservation $\mathrm{x}$ period of storage of eggs. Through the thermal images it was possible to observe that refrigerated eggs maintain better structure, contributing to a better quality egg, so the use of image is able to measure parameters for egg analysis in a non-destructive way.
\end{abstract}

\footnotetext{
${ }^{1}$ Engenheiro Agrícola, Professor, Instituto Federal do Mato Grosso do Sul, grazieli.suszek@ifms.edu..br

2 Agronomia, Instituto Federal do Mato Grosso do Sul, walter.decleva@estudante.ifms.edu..br

${ }^{3}$ Veterinária, Universidade Estadual de Maringá, andressanobrega@live.com

${ }^{4}$ Zootecnista, Professor, Instituto Federal do Mato Grosso do Sul, ana.royer@ifms.edu..br

${ }^{5}$ Engenheiro Agrícola, Professor, Instituto Federal do Mato Grosso do Sul, mauro.lima@ifms.edu..br
} 
Keywords: Thermal images, Destructive, Temperature, Quality

\section{Introdução}

O ovo sempre foi um alimento com alta taxa de consumo no Brasil, principalmente por ser nutricionalmente completo, possuir grande quantidade de proteína e ter um custo relativamente baixo. A refrigeração não é obrigatória no Brasil, assim os ovos comerciais são acondicionados, desde o momento da postura até a distribuição final, em temperaturas não controladas, sendo, em alguns casos, refrigerados apenas nas casas dos consumidores. MENDES (2010) explica que a qualidade dos ovos de consumo inclui um conjunto de características que define a aceitabilidade do produto pelos consumidores, sendo determinada por diversos aspectos externos e internos. Os aspectos externos referentes à qualidade do ovo estão relacionados à qualidade da casca, ao considerar sua estrutura e higiene. Ainda afirma que os aspectos internos consideram características relativas ao albúmen, gema, câmara de ar, cor, odor, sabor e manchas de sangue, determinadas somente após a quebra do ovo.

Uma das medidas mais utilizadas para avaliação da qualidade dos ovos é a Unidade Haugh (UH), que apesar das críticas a respeito da unidade, possui grande importância na avicultura de postura (ALLEONI e ANTUNES, 2001).

Esse método é uma expressão matemática que correlaciona a altura do albúmen espesso, obtida através de micrômetro tripé, corrigida para o peso do ovo. Sendo que, quanto maior o valor da UH melhor a qualidade do ovo, pois à medida que ele envelhece a proporção de albumina líquida aumenta em detrimento da densidade. A perda de gás carbônico resulta em uma alteração no sabor do ovo em decorrência do aumento da alcalinidade, além das inúmeras reações químicas que ocorrem no seu interior, envolvendo o ácido carbônico (H2CO3,) (MORENG e AVENS, 1990).

SOUZA et al. (2001) destacam que em ovos sob condições de temperatura ambiente, são afetadas negativamente as características físicas da casca, albúmen e gema, bem como a qualidade interna do ovo como um todo. De acordo com o Programa de Controle da Qualidade preconizado pelo Departamento de Agricultura Americano, ovos considerados de qualidade excelente devem apresentar valores de UH acima de 72; ovos de qualidade alta, entre 60 e 72 UH (Egg..., 2000). Além disso, autores como SCOTT \& SILVERSIDES (2000) e ALLEONI E ANTUNES (2001) argumentam que com a estocagem dos ovos, ocorre aumento do pH e diminuição da altura do albúmen (AA), com consequente 5 diminuições 
dos valores de UH. Ocorre também perda de peso do albúmen, que resulta em diminuição do peso do ovo.

Esses fatos foram observados por JONES et al. (2002) em sua pesquisa, na qual constataram que para a manutenção da alta qualidade dos ovos o tempo e a temperatura são fatores importantes que devem ser controlados durante o período de armazenamento, corroborando com os resultados obtidos por VÉRAS et al. (1999) e BARBOSA et al. (2004) que constataram que o peso dos ovos e as unidades Haugh foram alterados em função do tempo e do ambiente de armazenamento.

SANTOS et al. (2009) também estudaram o efeito da temperatura e estocagem em ovos e concluíram que o aumento do período de estocagem, independente da temperatura de conservação, ocasionou perda de peso dos ovos e reduções na gravidade específica, nas unidades Haugh e na coloração da gema crua. Os ovos mantidos em temperatura de refrigeração apresentaram menor perda de peso e melhores índices de porcentagem de clara, gravidade específica, unidades Haugh e coloração da gema crua, quando comparados aos ovos conservados em temperatura não controlada.

Em se tratando de qualidade, LEANDRO et al. (2005) comentaram que a redução da qualidade interna dos ovos está associada, principalmente, à perda de água e de dióxido de carbono, durante o período de estocagem. Esta perda é proporcional à elevação da temperatura do ambiente, pois acelera as reações físico-químicas levando à degradação da estrutura da proteína presente na albumina espessa, tendo como produto das reações a água ligada às grandes moléculas de proteínas que passam para a gema por osmose. Neste contexto a busca por forma de análises não destrutivas que possibilitam o monitoramento de parâmetros que permitem avaliar a qualidade do ovo torna-se importante para o setor produtivo.

Assim a termografia é uma técnica que permite o registro do campo de temperaturas de uma cena focalizada, através da medição da energia radiante infravermelha emitida pelos objetos do campo de visão da câmera termográfica. Logo, com a utilização de câmera térmica é possível visualizar e analisar como a temperatura e o tempo de armazenamento influenciam na qualidade dos ovos.

\section{Material e Métodos}

O experimento foi desenvolvido em laboratório com ovos de aves da linhagem Embrapa 51 acondicionadas em um galpão para aves de postura pertencente ao Instituto Federal de Mato Grosso do Sul, câmpus Nova Andradina. 
Estudou-se o efeito isolado e a interação de dois fatores: temperatura de conservação (temperatura não controlada e de refrigeração) e período de estocagem (fresco, 7, 14 e 21 dias) resultando no fatorial $2 \times 3$, o que correspondeu a 6 combinações de temperatura $\times$ período de estocagem com 4 repetições de 4 ovos/cada em que cada ovo representou uma unidade experimental. Os dados observados foram avaliados mediante análise de variância com o auxílio do programa estatístico SISVAR e as médias, quando significativas, foram submetidas à comparação ao teste de Tukey a 5\% de significância. Os ovos foram coletados no período da tarde, identificados e armazenados à temperatura não controlada, entre 24 a $36^{\circ} \mathrm{C}$, e em ambiente refrigerado entre 5 a $8^{\circ} \mathrm{C}$.

As imagens térmicas foram obtidas com uma câmera térmica Flir one®pro lightning, com precisão de +2 oC, resolução térmica de 120 x 160 pixels e com faixa de temperatura de -20 oC a +400 oC. Para isso a câmera foi posicionada a $15 \mathrm{~cm}$ do alvo, colocado em local plano e iluminado naturalmente, conforme mostrado na Figura 1.

Figura 1: Imagem térmica.

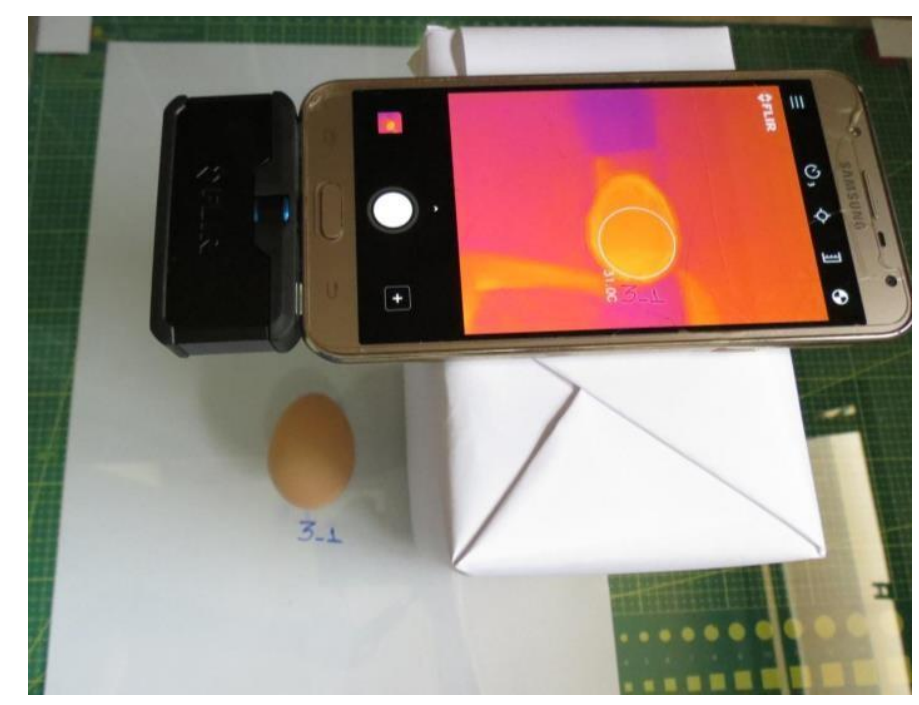

Fonte: Própria (2020)

As imagens foram processadas utilizando software de processamento de imagens Flir Tools®, sendo avaliados quanto a diferença de temperatura e investigada a anatomia do ovo, conforme Figura 2.

Na Figura 2 apresenta-se a anatomia do ovo, com suas estruturas externas e internas. Conforme a Figura 2 em destaque, as membranas dividem-se em interna e externa e é composta por uma rede de fibras protéicas que envolvem o albúmen e a câmara de ar no pólo maior do ovo, onde as membranas encontram-se separadas, sendo importante para manutenção do ovo. 
Figura 2: Anatomia de um ovo

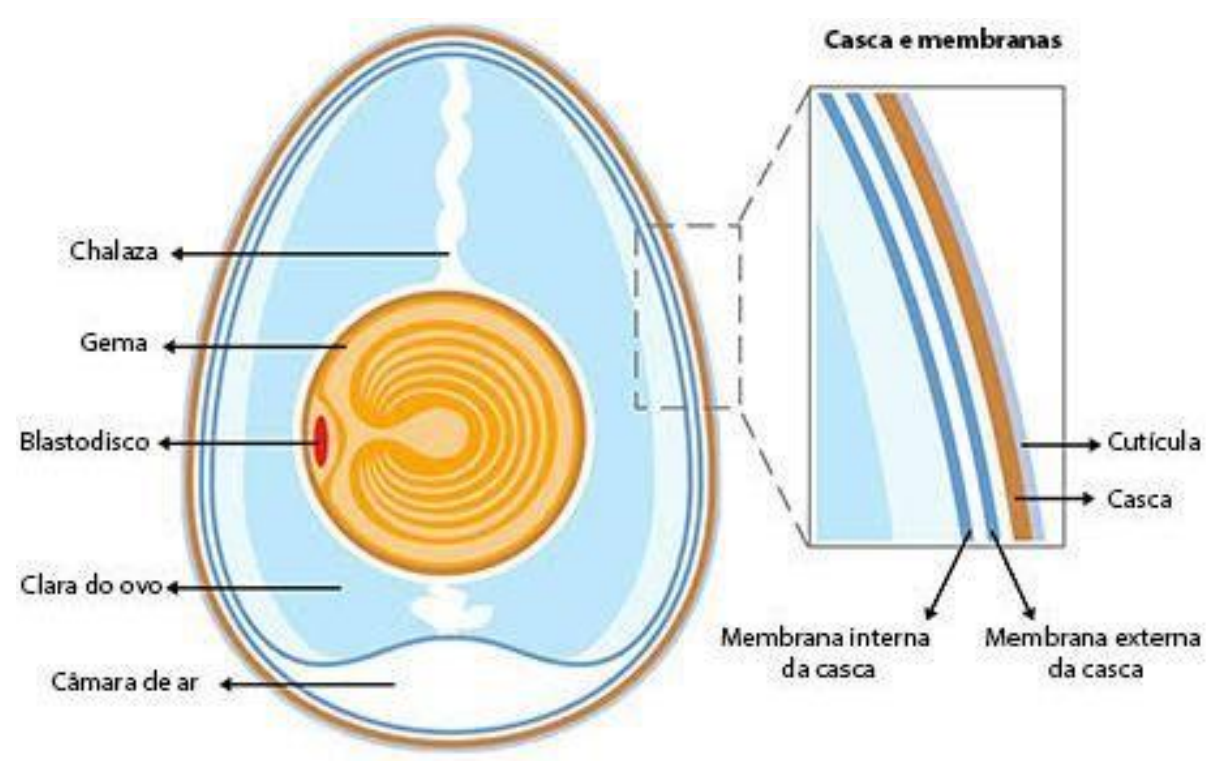

Fonte: Horst (2007)

A perda de peso dos ovos (\%), seguiu a metodologia proposta por BARBOSA et al., (2004), onde os ovos foram pesados no primeiro dia do período experimental e armazenados. Ao final do período experimental, os ovos de cada tratamento foram novamente pesados e pela diferença entre o peso no início e no final do tempo de armazenagem, mensurou-se a perda de peso em gramas de 6 amostras. Este valor foi dividido pelo peso do ovo no início do armazenamento e multiplicado por cem, gerando os dados de perda de peso em porcentagem.

As variáveis avaliadas foram perda de peso dos ovos (\%) e as características relativas à qualidade interna e externa dos ovos, sendo as externas: tamanho (Figuras 3 e 4) e peso (Figura 5) e de acordo com JARDIM filho et al., (2008) variáveis internas: Unidade Haugh, porcentagem de gema, porcentagem de albúmen e espessura de casca. 
Figura 3: Determinação do diâmetro do ovo.

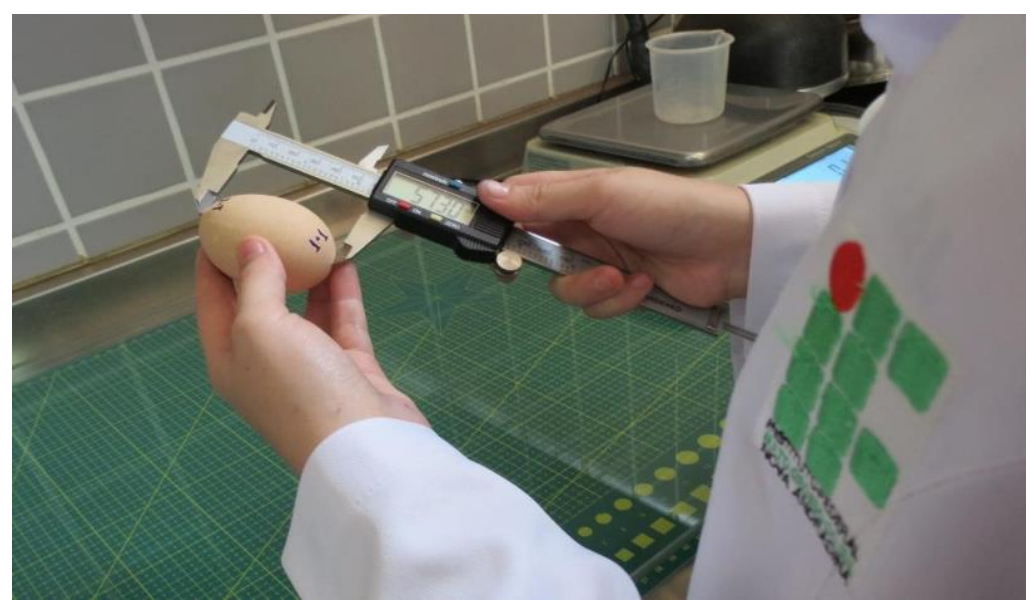

Fonte: Própria (2020)

Figura 4: Tamanho do ovo.

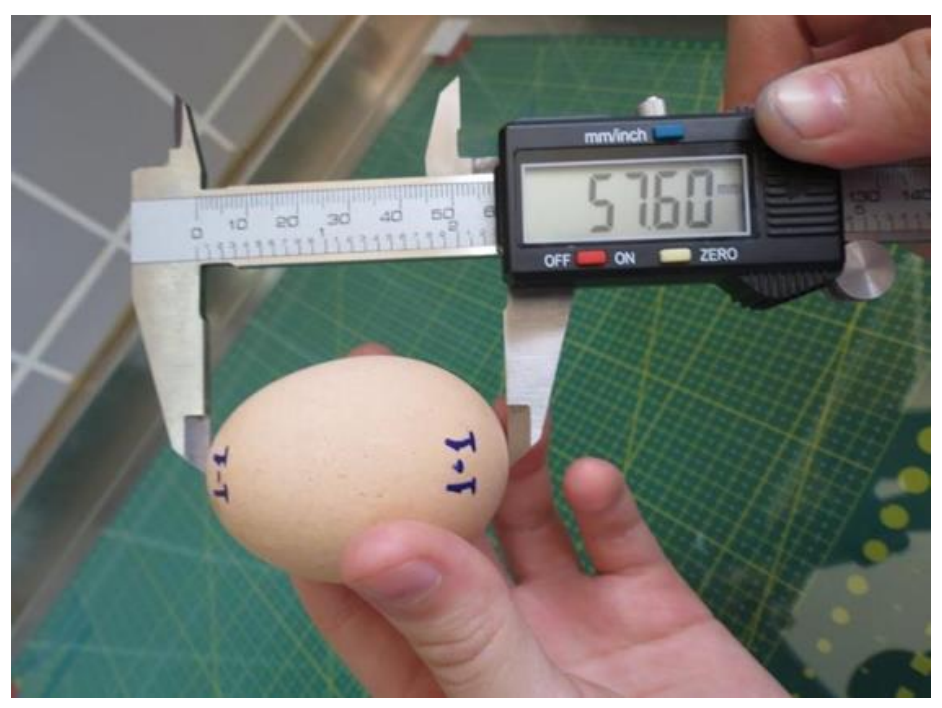

Fonte: Própria (2020)

Figura 5: Pesagem do ovo

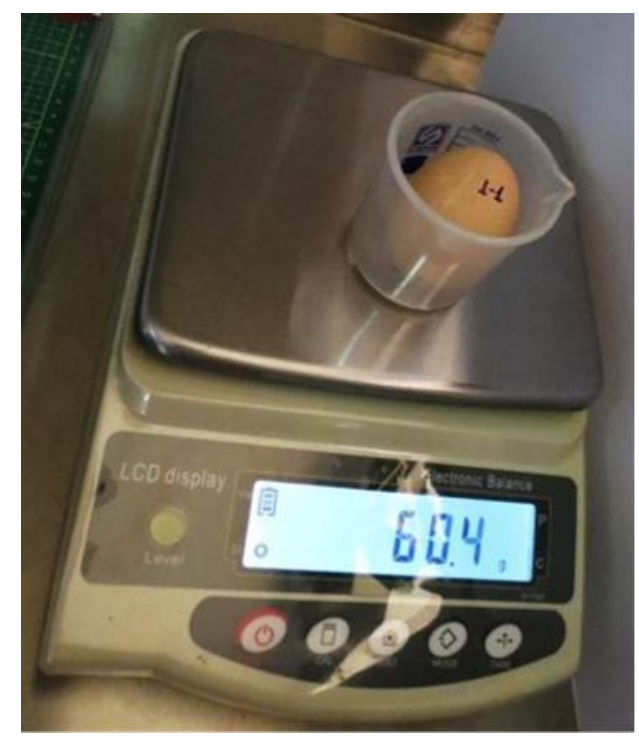

Fonte: Própria (2020) 
Para a determinação da Unidade Haugh os ovos foram quebrados sobre uma superfície plana de vidro (Figura 6) para a obtenção da altura e diâmetro de albúmen e da altura, diâmetro e peso de gema com uso de micrômetro e balança digital (Figuras 7, 8, 9, 10 e 11). A porcentagem de albúmen foi determinada por diferença: 100 - (\% de gema $+\%$ de casca $)$.

Figura 6: Ovo sobre superfície de vidro

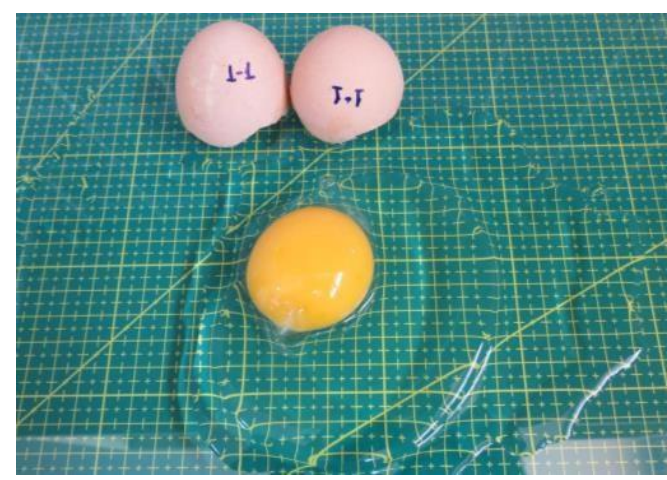

Figura 8: Diâmetro de albúmen.

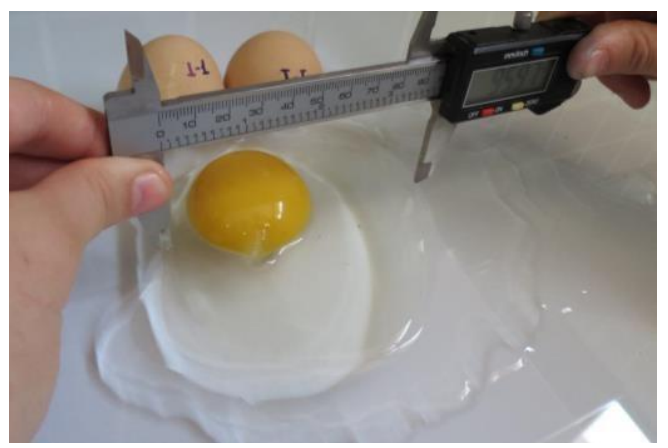

Figura 10: Diâmetro de gema.

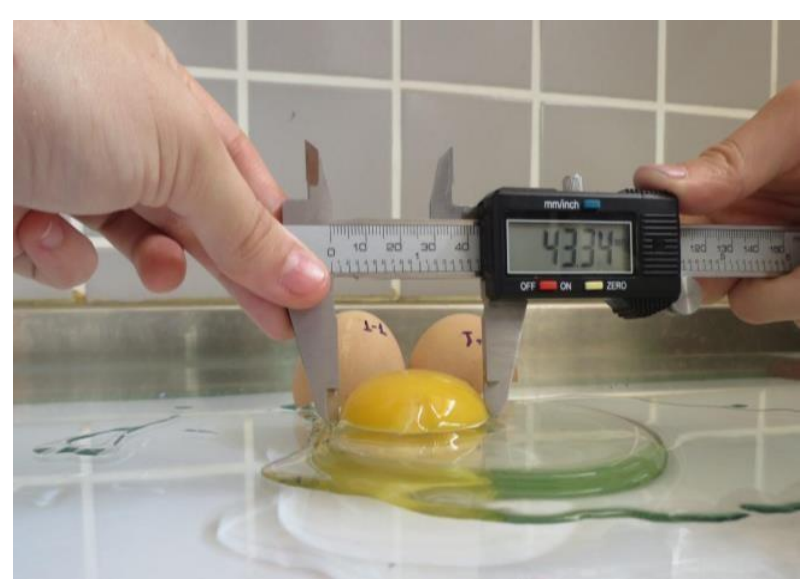

Figura 7: Altura de albúmen.

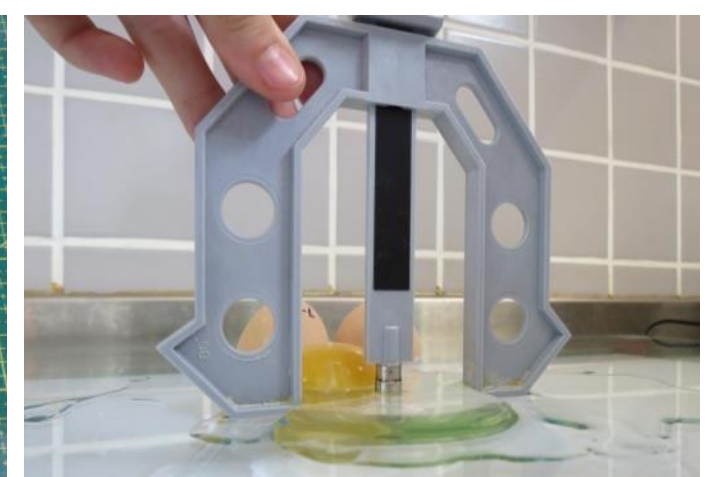

Figura 9: Altura de gema.

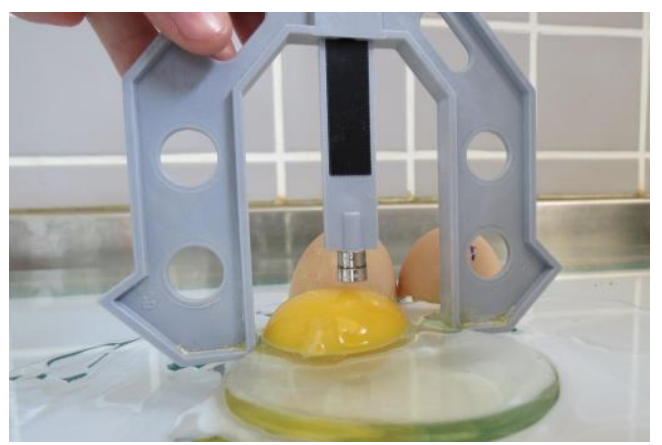

Figura 11: Peso de gema.

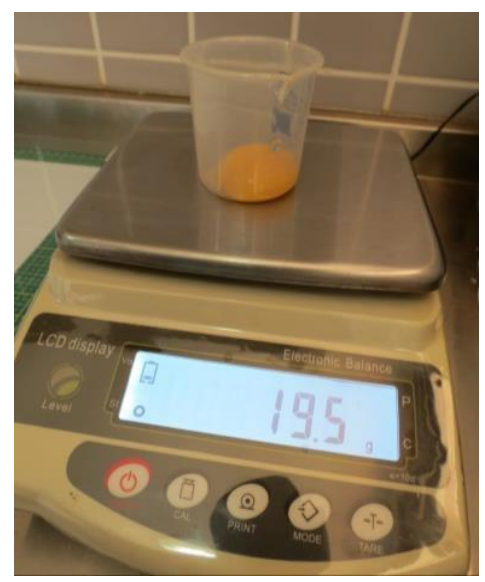

Fonte: Própria (2020)

As cascas resultantes dessa quebra foram lavadas e secas em temperatura ambiente e depois pesadas para o cálculo da porcentagem de casca (Figura 12).

Posteriormente, foram determinadas suas espessuras com medidas em três pontos distintos da região mediana, sendo utilizado micrômetro digital (Figura 13). 
Figura 12: Peso de casca.

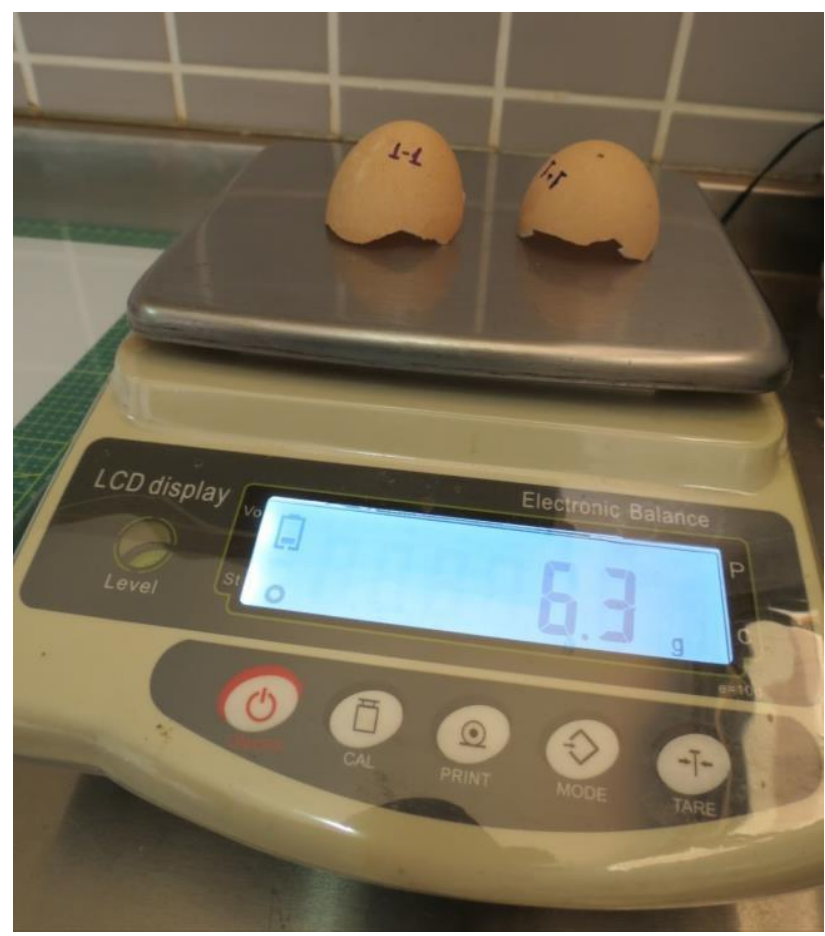

Fonte: Própria (2020)

Figura 13: Espessura de casca

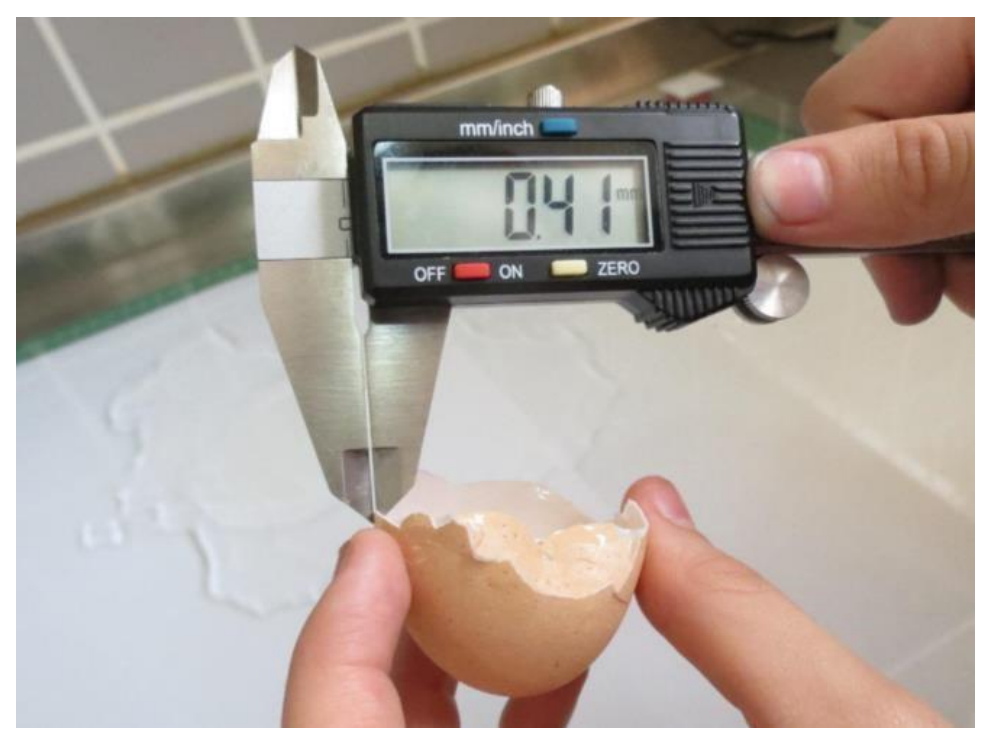

Fonte: Própria (2020)

\section{Resultados e Discussão}

Na tabela 1 encontram-se os resultados do efeito da temperatura e período de estocagem sobre a qualidade dos ovos de poedeiras comerciais avaliados no galpão avícola do IFMS Campus de Nova Andradina. Observou-se que nas temperaturas não controladas e refrigerados os ovos estocados durante 21 dias obtiveram perda de peso com relação a 7 e 14 dias, apesar de não apresentar diferença significativa segundo análise de Tukey a 5\%. 
Ocorreu essa perda de peso, provavelmente, devido à redução de água do albúmen (proporção diminui em função do período de estocagem), como pode ser observado no resultado para \% do albúmen dos ovos.

Em 21 dias de estocados, os resultados médios obtidos de porcentagem da gema na temperatura não controlada, apresentam maior peso do que em 7 e 14 dias, pois à medida que o ovo envelhece, a umidade do albúmen incorpora-se à gema, aumentando seu tamanho. Já com relação a albúmen, a relação é inversa, pois quando mantidas em temperatura não controlada, a porcentagem de albúmen foi menor quanto a refrigeração (14 e 21 dias de estocagem). ORNELLAS (1979) e SANTOS et al. (2009), relataram que, à medida que o ovo envelhece, a albúmen vai perdendo sua consistência, verificado também durante o processo de análise de qualidade, onde observou-se dificuldades de mensuração do albúmen com 21 dias de estocagem a temperatura não controlada.

Tabela 1. Efeito da temperatura e período de estocagem sobre a qualidade dos ovos de poedeiras comerciais avaliados no galpão avícola do IFMS Campus de Nova Andradina.

\begin{tabular}{|c|c|c|c|c|}
\hline \multirow{2}{*}{ Temperatura } & \multicolumn{4}{|c|}{ tempo de estocagem } \\
\hline & Frescos & 7 dias & 14 dias & 21 dias \\
\hline & \multicolumn{4}{|c|}{ Peso do ovo } \\
\hline Ambiente & $63,72^{A}$ & $62,82^{2 \mathrm{~A}}$ & $66,25^{\text {aA }}$ & $58,97^{\mathrm{aA}}$ \\
\hline \multirow[t]{2}{*}{ Refrigeração } & - & $61,62^{2 \mathrm{~A}}$ & $64,92^{\mathrm{aA}}$ & $58,08^{\mathrm{aA}}$ \\
\hline & \multicolumn{4}{|c|}{ Temperatura do Ovo } \\
\hline Ambiente & $30,05^{c}$ & $28,95^{\mathrm{bB}}$ & $32,35^{\mathrm{bB}}$ & $25,52^{\mathrm{bA}}$ \\
\hline \multirow[t]{2}{*}{ Refrigeração } & - & $5,52^{\mathrm{aA}}$ & $7,3^{\mathrm{aA}}$ & $4,3^{\mathrm{aA}}$ \\
\hline & \multicolumn{4}{|c|}{ Unidades Haugh dos ovos (UH) } \\
\hline Ambiente & $84,65^{\mathrm{B}}$ & $66,09^{\mathrm{aAB}}$ & $29,95^{\text {aA }}$ & $46,02^{\mathrm{aAB}}$ \\
\hline \multirow[t]{2}{*}{ Refrigeração } & - & $86,05^{\mathrm{b}}$ & $85,26^{\mathrm{bA}}$ & $73,98^{\mathrm{bA}}$ \\
\hline & \multicolumn{4}{|c|}{ Percentagem da gema nos ovos } \\
\hline Ambiente & $30,39^{A}$ & $32,83^{\mathrm{aA}}$ & $31,67^{\mathrm{bA}}$ & $33,6^{\mathrm{aA}}$ \\
\hline \multirow[t]{2}{*}{ Refrigeração } & - & $31,45^{\text {aA }}$ & $32,53^{\mathrm{aA}}$ & $33,4^{\mathrm{aA}}$ \\
\hline & \multicolumn{4}{|c|}{ Percentagem do albúmen nos ovos } \\
\hline Ambiente & $60,68^{\mathrm{aB}}$ & $57,94^{\text {aA }}$ & $59,29^{\mathrm{aAB}}$ & $57,08^{a A}$ \\
\hline \multirow[t]{2}{*}{ Refrigeração } & - & $59,85^{\text {aA }}$ & $59,20^{\mathrm{bA}}$ & $58,08^{a A}$ \\
\hline & \multicolumn{4}{|c|}{ Percentagem da casca nos ovos } \\
\hline Ambiente & $8,92^{\mathrm{aA}}$ & $9,23^{\mathrm{aA}}$ & $9,04^{\mathrm{aA}}$ & $9,31^{\text {aA }}$ \\
\hline \multirow[t]{2}{*}{ Refrigeração } & - & $8,69^{\mathrm{aA}}$ & $8,27^{\mathrm{aA}}$ & $8,51^{\mathrm{aA}}$ \\
\hline & \multicolumn{4}{|c|}{ Índice de Gema (IG) } \\
\hline Ambiente & $0,42^{\mathrm{C}}$ & $0,35^{\mathrm{aB}}$ & $0,27^{\mathrm{aA}}$ & $0,26^{a A}$ \\
\hline Refrigeração & & $0,47^{\mathrm{bA}}$ & $0,46^{\mathrm{bA}}$ & $0,50^{\mathrm{bA}}$ \\
\hline
\end{tabular}

Nas colunas, médias seguidas por pelo menos uma letra minúscula igual não difere estatisticamente entre si, pelo teste de Tukey ( $>$ > 0,05); nas linhas, médias seguidas por pelo menos uma letra maiúscula igual não difere estatisticamente entre si, pelo teste de Tukey $(\mathrm{p}>0,05)$. 
Em ambas as temperaturas a porcentagem de casca foi maior em 7 e 21 dias. Em temperatura não controlada, independentemente do tempo de estocagem, os ovos apresentaram menor valor de unidades Haugh, quando comparados aos ovos mantidos refrigerados.

O presente estudo, conforme Tabela 2, constatou que houve interação significativa entre a temperatura de conservação e o período de estocagem dos ovos em relação aos: parâmetros de unidades Haugh, \% de gema, \% de albúmen e IG. Assim, verifica-se a existência de interdependência entre os fatores temperatura de conservação x período de estocagem dos ovos, para os parâmetros citados.

Tabela 2. Comportamento das interações temperatura de conservação $\times$ período de estocagem $(\mathrm{T} \times \mathrm{E})$ sobre diversos parâmetros.

\begin{tabular}{|l|c|}
\hline Parâmetros & Significância (T $\times \mathrm{E})$ \\
\hline Peso do ovo & $\mathrm{NS}$ \\
\hline Temperatura do Ovo & $\mathrm{S}$ \\
\hline Unidades Haugh dos ovos (UH) & $\mathrm{S}$ \\
\hline Percentagem da gema nos ovos & $\mathrm{NS}$ \\
\hline Percentagem do albúmen nos ovos & $\mathrm{S}$ \\
\hline Percentagem da casca nos ovos & $\mathrm{S}$ \\
\hline Índice de Gema (IG) & \\
\hline
\end{tabular}

$S=$ significativo $(p<0,05)$; e NS = não significativo $(p>0,05)$.

Verificou-se que os ovos mantidos refrigerados apresentaram menor perda de peso e melhores índices de percentagem do albúmen, unidades Haugh e índice de gema, quando comparados aos ovos conservados em temperatura não controlada. O aumento do período de estocagem dos ovos, independente da temperatura de conservação, ocasionou perda na estrutura dos ovos, porém verificou-se reduções na unidade Haugh e índice de gema nos mantidos à temperatura não controlada conforme maior o período de estocagem.

Através da utilização da câmera térmica foi possível a obtenção das imagens apresentadas na Figura 14.

Verificou-se que os ovos armazenados em temperatura não controlada tiveram uma degradação maior nas propriedades internas, podendo ser verificado nas imagens que os ovos se mantiveram em temperaturas altas, nos ovos refrigerados, observou-se uma conservação da sua estrutura durante os 21 dias de armazenamento. 
Figura 14: Comparação entre imagens térmicas de ovos armazenados em temperatura não controlada e sob refrigeração.
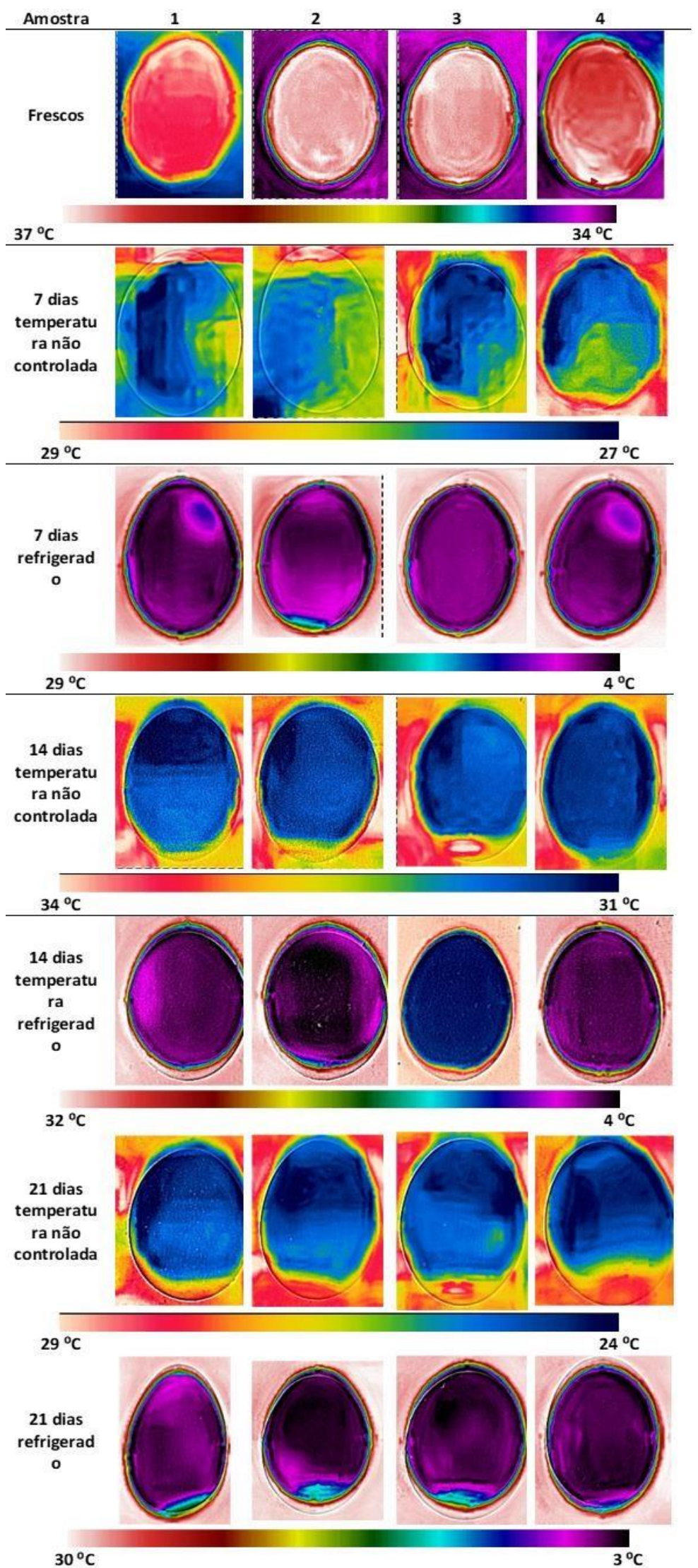

Fonte: Própria (2020) 
Conforme pode ser observado na Figura 15, com 21 semanas os ovos que foram mantidos sob refrigeração a manutenção das estruturas (Figura 5) foi também conservada sendo observada também a câmara de ar no canto inferior direito. Por fim esse método para análise de ovos, utilizando imagens térmicas pode contribuir para análise não destrutiva de qualidade de ovos em produção comercial, precisando, porém, de mais análises científicas para validação.

Figura 15: Observação das membranas interna e externa do ovo armazenado em refrigeração após 21 dias, feitas através do uso de imagens térmicas, e no canto inferior direito a câmara de ar.

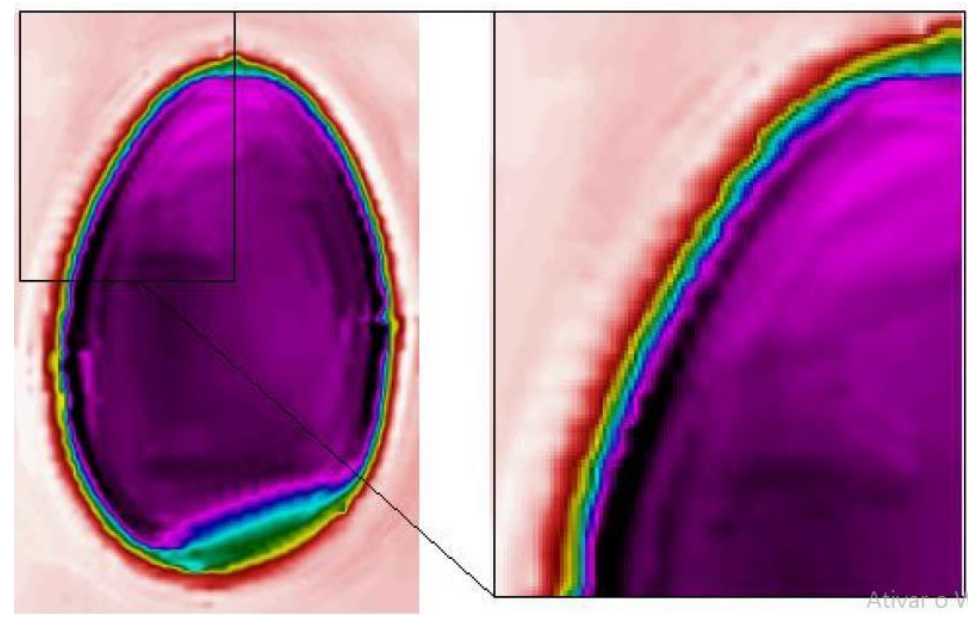

Fonte: Própria (2020)

\section{Conclusões}

Verificou-se a existência de interdependência entre os fatores temperatura de conservação x período de estocagem dos ovos, para os parâmetros citados. Ovos mantidos refrigerados apresentaram menor perda de peso e melhores índices de percentagem do albúmen, unidades Haugh e índice de gema, quando comparados aos ovos conservados em temperatura não controlada durante todo o tempo de armazenamento.

Contata-se que é possível pelas imagens térmicas observar que ovos refrigerados mantêm melhor estrutura, contribuído para um ovo de melhor qualidade. Foi percebido visualmente a localização da câmara de ar, nos ovos refrigerados com 21 semanas.

Desta forma, a utilização de imagens térmicas pode ser capaz de mensurar parâmetros para análise de ovos, contribuindo, portanto, para análise não destrutiva de qualidade de ovos em produção comercial

\section{Referências}

ALLEONI, A. C. C., ANTUNES, A. J. Unidade Haugh como medida da qualidade de ovos de galinha armazenados sob refrigeração. Scientia Agrícola, Piracicaba, v. 58, n. 4, p. 681 - 685, 
2001. Disponível em: 〈http://www.scielo.br/pdf/sa/v58n4/6283.pdf>. Acesso em: 26 de abril de 2018.

BARBOSA, N. A. A. et al. Efeito da temperatura e do tempo de armazenamento na qualidade interna de ovos de poedeiras comerciais. Brazilian Journal Poultry Science, v. 60, n. Supl 6, p. 60-65, 2004.

EGG-Grading Manual. Washington: Department of Agriculture/Agricultural Marketing Services. 2000. (Agricultural Handbook, 75). Disponível em:

<https://naldc.nal.usda.gov/download/CAT11094176/PDF>. Acesso em: 17 de outubro de 2019.

HAUGH, R. R. The Haugh unit for measuring egg quality. United States Egg Poultry Magazine, v.43, p.552-555, 1937.

HORST, F. Anatomia de um ovo. 2007

Instituto Brasileiro de Geografia e Estatística. Indicadores IBGE: Estatística da Produção Pecuária março de 2018. Rio de Janeiro: Instituto Brasileiro de Geografia e Estatística; 2018. Disponível em:

<https://biblioteca.ibge.gov.br/visualizacao/periodicos/2380/epp_2018_mar.pdf>. Acesso em 26 abril 2018.

JONES, D. R. et al. Effects of cryogenic cooling of shell eggs on egg quality. Poultry Science, v.81, n. 5, p. 727-733, 2002. Disponível em: <https://doi.org/10.1093/ps/81.5.727> Acesso em: 17 de outubro de 2019.

LEANDRO, Nadja Susana Mogyca et al. Aspectos de qualidade interna e externa de ovos comercializados em diferentes estabelecimentos na região de Goiânia. 2005. Disponível em: <https://www.revistas.ufg.br/vet/article/view/358/333>. Acesso em: 17 de outubro de 2019.

MENDES, F. R. Qualidade física, química e microbiológica de ovos lavados armazenados sob duas temperaturas e experimentalmente contaminados com Pseudomonas aeruginosa. 2010.72f. Dissertação (Mestrado em Ciência Animal) - Escola de Veterinária, Universidade Federal de Goiás, Goiânia. Disponível em:

〈https://ppgca.evz.ufg.br/up/67/o/Tese2014_Sandra_Gherardi.pdf >. Acesso em: 26 de abril de 2018.

MORENG, R.E.; AVENS, J.S. Ciência e produção de aves. São Paulo: Roca, 1990. p. 227249.

ORNELLAS, L. H. Técnica dietética 3. ed. Rio de Janeiro, Júlio C. Reis-Livraria, 1979.

PISSINATI, A.; OBA, A.; YAMASHITA, F.; SILVA, C. A.; PINHEIRO, J. W.; ROMAN, J. M. M.

Internal quality of eggs subjected to different types of coating and stored for 35 days at $25^{\circ} \mathrm{C}$.

Semina: Ciências Agrárias, v.35, n.1, p.531-540, 2014. Disponível em: 
<http://www.uel.br/revistas/uel/index.php/semagrarias/article/view/13587/14099>. Acesso em: 24 de julho.

SANTOS, Maria do Socorro Vieira et al. Efeito da temperatura e estocagem em ovos.

Ciência e Tecnologia de Alimentos, v. 29, n. 3, p. 513-517, 2009. Disponível em:

<http://www.scielo.br/pdf/cta/v29n3/a09v29n3.pdf>. Acesso em: 17 de outubro de 2019.

SOUZA, P. A. Ovos e refrigeração. Avicultura Industrial, São Paulo, v.3, p. 44-45, 2001.

SCOTT, T. A.; SILVERSIDES, T. B. The effect of storage and strain of hen on egg quality.

Poultry Science, v.79, p.1725-1729, 2000. Disponível em:

<https://doi.org/10.1093/ps/79.12.1725>. Acesso em: 23 de julho de 2019.

VÉRAS, A. L. et al. Avaliação da qualidade interna de ovos armazenados em dois ambientes em diferentes tempos. Conferência APINCO de ciência e Tecnologia Avícolas. Trabalhos de Pesquisa Avícola. São Paulo. Brazilian Journal Poultry Science, supl. Prêmio Lamas, p. 55, 1999. 